\title{
Publisher Correction: Structural underpinnings of oestrogen receptor mutations in endocrine therapy resistance
}

\author{
John A. Katzenellenbogen, Christopher G. Mayne, Benita S. Katzenellenbogen, \\ Geoffrey L. Greene and Sarat Chandarlapaty
}

Nature Reviews Cancer (2018) https://doi.org/10.1038/s41568-018-0001-Z

Published online April 2018

The originally published article contained an error in the legend of supplementary figure 1. A figure permission line was left off. The correct figure permission line has now been added to the HTML and PDF versions of the article, stating that "Data shown in (B) and (C) of this figure were originally published in Jeyakumar, M., Carlson, K. E., Gunther, J. R. \& Katzenellenbogen, J. A. Exploration of dimensions of estrogen potency: parsing ligand binding and coactivator binding affinities. J. Biol. Chem. 286, 12971-12982, (2011) (c) the American Society for Biochemistry and Molecular Biology (Ref. 53)."

https://doi.org/10.1038/s41568-018-0053-0 I Published online 5 September 2018

\section{Publisher Correction: The molecular landscape of head and neck cancer}

C. René Leemans, Peter J. F. Snijders and Ruud H. Brakenhoff

Nature Reviews Cancer (2018) https://doi.org/10.1038/nrc.2018.11

Published online 2 March 2018

The article as originally published contained errors in Figure 3. The direction of the arrows associated with the labels for $\mathrm{p} 53$ and RB were incorrect. This has now been corrected in all versions of the article.

https://doi.org/10.1038/s41568-018-0057-9 I Published online 12 September 2018 